\title{
Laser Induced Anchoring of Nickel Oxide Nanoparticles on Polymeric Graphitic Carbon Nitride Sheets Using Pulsed Laser Ablation for Efficient Water Splitting under Visible Light
}

\author{
Umair Baig ${ }^{1}$, Abuzar Khan ${ }^{2}\left(D\right.$, Mohammad A. Gondal ${ }^{3, *}$, Mohamed A. Dastageer ${ }^{3}$ \\ and Wail S. Falath ${ }^{1,4}$ \\ 1 Center of Research Excellence in Desalination \& Water Treatment and Center for Environment and Water, \\ King Fahd University of Petroleum and Minerals, Dhahran 31261, Saudi Arabia; \\ umairbaig@kfupm.edu.sa (U.B.); wfallata@kfupm.edu.sa (W.S.F.) \\ 2 Center for Research Excellence in Nanotechnology, King Fahd University of Petroleum and Minerals, \\ Dhahran 31261, Saudi Arabia; abuzar@kfupm.edu.sa \\ 3 Department of Physics and Center for Research Excellence in Nanotechnology, \\ King Fahd University of Petroleum and Minerals, Dhahran 31261, Saudi Arabia; makader@kfupm.edu.sa \\ 4 Department of Mechanical Engineering, King Fahd University of Petroleum and Minerals, \\ Dhahran 31261, Saudi Arabia \\ * Correspondence: magondal@kfupm.edu.sa; Tel.: +96-6386-02351 or +96-6386-03274
}

Received: 21 April 2020; Accepted: 19 May 2020; Published: 2 June 2020

\begin{abstract}
A visible-light-active nickel oxide-graphitic carbon nitride (NiO@g-CN) hetero-structured nanocomposite was synthesized for the first time by pulsed laser ablation in liquid and used as a photoanode material in photoelectrochemical water-splitting reaction with a solar simulator. It was found that the photoelectrochemical performance of PLAL synthesized NiO@g-CN nanocomposite as photoanode, compared to g-CN as photoanode showed fourfold enhancements in photocurrent density under visible light. FT-IR, XRD, FE-SEM, and EDX consistently showed the proper anchoring of nano-sized $\mathrm{NiO}$ on g-CN. UV-DRS and the band gap estimation showed the narrowing down of the band gap energy and consequent enhancement in the visible-light absorption, whereas photoluminescence spectroscopy confirmed the reduction of the recombination of photo-excited electron hole pairs as a result of the anchoring of $\mathrm{NiO}$ on $\mathrm{g}-\mathrm{CN}$. The photoelectrochemical performance of g-CN and the NiO@g-CN nanocomposite photoanodes was compared by linear sweep voltammetry (LSV), Chronoamperometry (I-t), and Electrochemical Impedance Spectroscopy (EIS). All of these results of the characterization studies account for the observed fourfold enhancement of photocurrent density of NiO@g-CN nanocomposite as photoanode in the photoelectrochemical reaction.
\end{abstract}

Keywords: nanocomposites; pulsed laser ablation; visible-light-active photocatalyst; PEC water splitting

\section{Introduction}

In the age of an ever-increasing need for energy and growing concern for the environment, the realization and utilization of carbon-free hydrogen fuel remain as the hope for catering to the global energy needs and mitigating the environmental damage caused by fossil fuels [1-4]. The current method widely used for hydrogen production is steam reforming of the natural gas, which cannot be a complete solution, as this method releases greenhouse gases in the atmosphere, and also the hydrogen 
production by electrolysis is not effective, as a lot of energy has to be expended to produce hydrogen. The level of $\mathrm{CO}_{2}$ in the atmosphere has already reached an alarmingly dangerous level, and if it is left unchecked, it will be very catastrophic for the environment and life on earth. The method of carbon capture and sequestration to convert $\mathrm{CO}_{2}$ into value added hydrocarbon is quite cumbersome and requires a huge amount of energy $[5,6]$. Hence, these methods of hydrogen production are not only economically profitable but also cause huge damage to the already fragile environment $[7,8]$. A simple photoelectrochemical method using n-type $\mathrm{TiO}_{2}$ (rutile) semiconductor as a photoanode and platinum as the counter electrode was successfully demonstrated by Fujishima et al., where the electrons generated as a result of the irradiation of $\mathrm{UV}$ light on $\mathrm{TiO}_{2}$ caused a flow of a photo-current to the counter electrode to photoanode, and this current was maintained even in the absence of bias voltage [9]. This pioneering work triggered many environmental and energy applications, such as photocatalytic water splitting [10], $\mathrm{CO}_{2}$ conversion into value added hydrocarbons [11,12], and water purifications $[13,14]$. The major focus for the utilization of photo-catalytic and photoelectrochemical methods has been the quest for the right materials, i.e., materials that are capable of harvesting the naturally abundant solar radiation and improve the efficiency by hampering the undesired negative reactions, like the inherent recombination of the photo-generated charge carriers.

Although $\mathrm{TiO}_{2}$ has been quite a ubiquitous photocatalyst for many photocatalytic and photoelectrochemical applications, such as hydrogen production, $\mathrm{CO}_{2}$ reduction, and environmental remediation $[15,16]$, its wider band-gap energy restricts its use in UV region, and in addition to this, the rapid recombination of photo-generated charge carriers is another disadvantage of this material. Besides $\mathrm{TiO}_{2}$, other semiconductors, like $\mathrm{NiO}, \mathrm{WO}_{3}, \mathrm{ZnO}, \mathrm{CdS}$, and $\mathrm{CdSe}$, in pure, doped, and composite forms, were developed by different groups that were aiming at improving the visible-light absorption and also reducing the charge recombination [17]. The formation of a metal semiconductor junction (Schottky junction) and a junction between two dissimilar semiconducting materials (heterojunction) shrinks the band-gap energy of the material, due to the reshuffling of the density of states, and also facilitates the spatial charge separation through the drifting of the charge carriers at the junction, due to the junction-induced electric field. These two newly evolved features in the composite materials ensure better visible-light-induced photocatalytic activity, with a reasonable enhancement of efficiency. Another factor to be considered for the applications of these materials for the photoelectrochemical water splitting, in particular, is that the conduction band energy should be more negative than the hydrogen reduction potential, in order to facilitate the photo-generated electrons to spontaneously migrate to the counter electrode, to carry out hydrogen reduction. However, in the absence of the above energy compatibility, the external bias should be used in the photoelectrochemical cell. Moreover, the electric field generated by the electrons impedes the reverse reaction, where the hydrogen and oxygen in the photochemical reaction combine to form water through an explosive reaction.

In the pursuit of finding a heterogeneous photocatalyst, metal-free polymeric graphitic carbon nitride g-CN has become the center of attraction in photocatalysis. Polymeric graphitic carbon nitride $(\mathrm{g}-\mathrm{CN})$ is a visible-light-active n-type semiconducting material with the band-gap energy of $2.7 \mathrm{eV}$. In addition to this, g-CN has other favorable features, such as an attractive electronic structure, cost-effectiveness, nontoxicity, environmental friendliness, and thermal and chemical stability [18-20]; hence, this material has been used for many visible-light-driven photocatalytic applications, such as water splitting and $\mathrm{CO}_{2}$ reduction [21]. In spite of the visible-light activity of g-CN close to the blue spectral region, the use of pure $\mathrm{g}-\mathrm{CN}$ is restricted by rapid photo-generated charge recombination, small surface area, due to the characteristics two-dimensional layered structure [22,23]. In order to minimize the rapid charge recombination and harness the positive features of $\mathrm{g}-\mathrm{CN}$, modifications like doping with metal and non-metals and compositing with other co-catalyst have been tried, and these kinds of material engineering have improved the photocatalytic activity of the material to a certain extent, in different applications [24-26]. Particularly, compositing n-type g-CN with different p-type semiconducting materials like $\mathrm{BiOCl}, \mathrm{CuS}$, and $\mathrm{SnS}_{2}$ has been tried, and it was reported that the resultant $\mathrm{p}-\mathrm{n}$ heterojunction facilitated the spatial charge separation and consequently resulted 
in the reduction of charge recombination, which was eventually manifested as the enhancement of photocatalytic efficiency. Hence, the p-n heterojunction of g-CN with any compatible p-type material is a proven method to enhance the photocatalytic activity $[27,28]$.

$\mathrm{NiO}$ is a p-type semiconductor, showing a perfect lattice match with g-CN; it also shows a compatible band energy structure to form type-II heterojunction with g-CN, which facilitates high charge mobility across the junction. Both the conduction band $(-1.95 \mathrm{eV})$ and valance band $(1.35 \mathrm{eV})$ of p-type $\mathrm{NiO}$ are at a higher energy position than the conduction band $(-0.95 \mathrm{eV})$ and the valance band $(1.70 \mathrm{eV})$ of n-type $\mathrm{g}-\mathrm{CN}$; hence, upon junction formation, the electric field is directed from g-CN side to $\mathrm{NiO}$ side, and this field drifts the electrons from the conduction band of $\mathrm{NiO}$ to that of g-CN accompanied by the drifting of holes from the valance band of $\mathrm{g}-\mathrm{CN}$ to that of $\mathrm{NiO}$, thereby establishing a spatial separation of photo-generated charge carriers and hence hinders the spontaneous charge recombination process. This reduced charge recombination promoted by the junction formation, coupled with the intactness of visible-light activity of g- $\mathrm{CN}$, ensures that $\mathrm{NiO}$ is a good co-catalyst with $\mathrm{g}-\mathrm{CN}$ for the photocatalytic applications, and for this same reason, this composite material can be a good material for the photoanode in photoelectrochemical applications [29,30].

Photocatalytic and photoelectrochemical activities of the semiconductor widely depend on the shape size and morphology of the synthesized material, and these factors are decided by the physical and chemical environment that prevails during the synthesis [31-35]. The well-established methods of synthesis by solvothermal, hydrothermal, and photochemical reduction have some major disadvantages, like the need for heavy instrumentation and post-purification, due to the use of various chemical intermediates. In recent years, the method of pulsed laser ablation in liquid (PLAL) is commonly used for the synthesis of pure and composite nano-structured materials, as the physical and morphological characteristics materials can be controlled by the laser parameters, such as laser wavelength and pulse laser duration, and by the $\mathrm{pH}$, added surfactant, and the temperature of the liquid medium used for the synthesis [16,36,37]. Moreover, unlike other conventional methods of synthesis, PLAL does not require heavy instrumentation and purification of the material after synthesis. In the PLAL method of synthesis, the plasma plume generated by the material laser interaction creates a cavitation bubble in the liquid medium, and the expansion and the collapse of the cavitation bubbles and the consequent formation of the shock wave critically contribute to the development of shape size and morphology of the synthesized nanoparticles. The complex physical change brought about by the shockwave and the cavitation bubble initiate a unique chemical reaction between the composite partners, determining the chemical characteristics of the nanocomposite.

In the present work, we employed the PLAL method of rapid synthesis of hetero-structured inorganic-organic nickel oxide-graphitic carbon nitride (NiO@g-CN) nanocomposite, and the optical, morphological, and structural characteristics of this material used out in this study proved the resultant composite material ( $\mathrm{NiO} @ \mathrm{~g}-\mathrm{CN}$ ) is visible-light active and imparts good inhibition to the recombination of photo-generated charge carriers. The synthesized g-CN and the NiO@g-CN nanocomposite were used as photoanodes in the photoelectrochemical water-splitting reaction, and it was found that the photoelectrochemical performance of PLAL-synthesized NiO@g-CN nanocomposite photoanode, compared to the g-CN photoanode, showed four-fold enhancement in photocurrent density under visible light. The PEC performance of g-CN and the NiO@g-CN nanocomposite photoanodes was compared by I-V, I-t characteristics, and EIS measurements. To the best of the knowledge, there is no report on the fast synthesis of a hetero-structured inorganic-organic NiO@g-CN nanocomposite by pulsed laser ablation in liquid technique as photoanode material for PEC water oxidation reaction. 


\section{Experimental}

\subsection{Reagents and Chemicals}

Nickel oxide ( $\mathrm{NiO}$ ) nanoparticles, Melamine, and other chemicals used in this study were purchased from Merck, Darmstadt, Germany. The solvents, such as acetone, ethanol, and methanol, were of high purity, and they were locally purchased. All the chemicals were used as purchased.

\subsection{Synthesis of Graphitic Carbon Nitride}

The g-CN powder was prepared by using a simple thermal pyrolysis technique. Melamine powder was used as precursor for the synthesis of g-CN. Firstly, Melamine powder was calcined for $2 \mathrm{~h}$ at $550{ }^{\circ} \mathrm{C}$, in a heating furnace, at a ramp rate of $20^{\circ} \mathrm{C} / \mathrm{min}$, and then the obtained powder, containing tri-s-triazine units, was further calcined for $2 \mathrm{~h}$ at $550{ }^{\circ} \mathrm{C}$, in a heating furnace, at a ramp rate of $20^{\circ} \mathrm{C} / \mathrm{min}$, to obtain the $\mathrm{g}-\mathrm{C}_{3} \mathrm{~N}_{4}$ powder.

\subsection{Synthesis of Nickel Oxide-Graphitic Carbon Nitride Nanocomposite}

A nickel oxide-graphitic carbon nitride nanocomposite (NiO@g-CN) was synthesized for the first time via pulsed laser ablation in liquid (PLAL), in the liquid medium of de-ionized water. High-energy laser radiations from the second harmonic of Q-Switched Nd:YAG laser (Brilliant B; $\lambda=532 \mathrm{~nm}$ ) were used. The pulse energy of the laser beam was maintained at $300 \mathrm{~mJ} / \mathrm{Pulse}$, the pulse duration was $5 \mathrm{~ns}$, and the pulse repetition was $10 \mathrm{~Hz}$. The laser beam was routed to a glass beaker, where it was focused into the liquid medium, using a lens of $50 \mathrm{~cm}$ focal length. The mixture of $\mathrm{g}-\mathrm{CN}$ and $\mathrm{NiO}$ was dispersed in $20 \mathrm{~mL}$ of de-ionized water, under ultrasonic vibrations, for $1 \mathrm{~h}$, and then irradiated with a laser beam for about $40 \mathrm{~min}$. In order to ensure homogeneous ablation, the mixture was stirred continuously, using a magnetic stirrer. After 40 min of irradiation, a NiO@g-CN nanocomposite solution was obtained, and it was dried at $80^{\circ} \mathrm{C}$, in an oven, for $2 \mathrm{~h}$, to obtain NiO@g-CN nanocomposite powder. The graphic representation for the synthesis of $\mathrm{NiO} @ \mathrm{~g}-\mathrm{CN}$ nanocomposite by PLAL is shown in Figure 1.

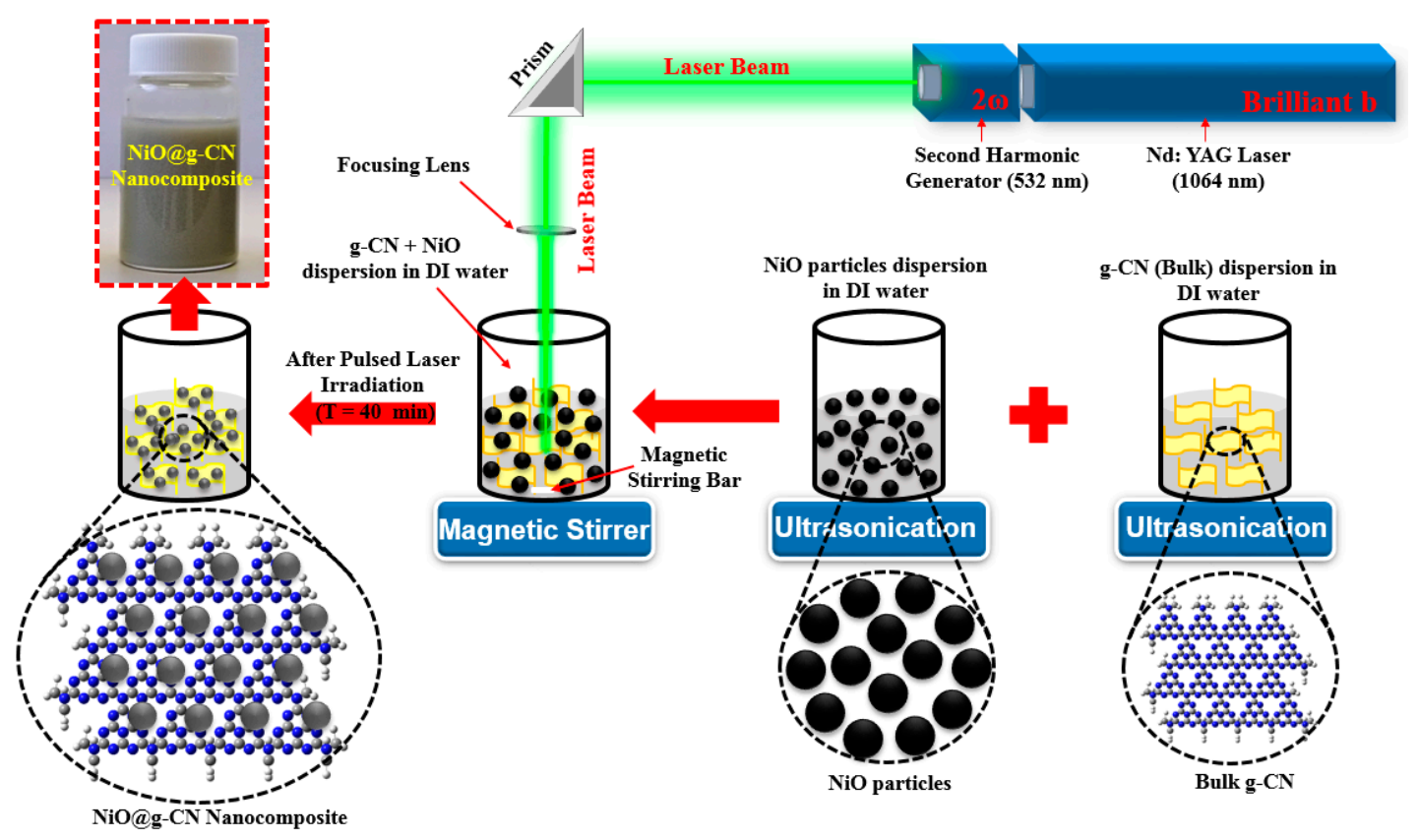

Figure 1. Schematic diagram for the synthesis of NiO@g-CN nanocomposite, using pulsed laser ablation in liquid approach. 


\subsection{Characterization}

FE-SEM images were taken by using Filed emission electron microscope (Lyra3, Tescan, Brno, Czech Republic), equipped with an energy dispersive EDX system. TEM and HR-TEM images were taken, using a JEOL (JEM-2100F) Transmission Electron Microscope (JEOL USA Inc., Peabody, MA, USA). X-ray diffraction (XRD 6000, Shimadzu, Kyoto, Japan) with Cu-K $\alpha$ radiation instrument was used for XRD studies. FT-IR spectra were obtained on a Nicolet 6700 FT-IR spectrometer IS50 (Thermo Electron Corp., Waltham, MA, USA), UV-DRS were obtained on a JASCO V-670 UV-VIS spectrophotometer (JASCO, Pfungstadt, Germany), and the PL emission spectra were acquired by Spectrofluorimeter (JASCO, FP-8500, Pfungstadt, Germany).

\subsection{Fabrication of Photoanodes and PEC Measurements}

The ink solution ( $2 \mathrm{~mL}$ ) of the photocatalysts was prepared in a vial containing an ethanol-and-water mixture (1:1). For the preparation of ink, $10 \mathrm{mg}$ of the photocatalyst was taken in a vial containing $2 \mathrm{~mL}$ of water-ethanol mixture (1:1), followed by an addition of $8 \mu \mathrm{L}$ of Nafion ${ }^{\circledR}$. The dispersion was homogenized by sonication for $1 \mathrm{~h}$. The film was prepared by drop-casting the ink solution on FTO kept on hot plate $\left(60^{\circ} \mathrm{C}\right)$. The ink solution on FTO covered an area of $1 \mathrm{~cm}^{2}$. The film was left on the hot plate until it was completely dried. The electrochemical characterization of the film was carried out in a 3-electrode assembly containing $0.5 \mathrm{M} \mathrm{Na}_{2} \mathrm{SO}_{4}$ electrolyte ( $\left.\mathrm{pH} 7.1\right)$. The film on FTO served as a photoanode, while the Saturated Calomel Electrode (SCE) and Pt electrode served as reference and counter electrode, respectively. The assembly was connected to an Autolab potentiostat supported by NOVA 2.0 software (NOVA 2.0, Metrohm Autolab). A solar simulator (Oriel Sol-AAA Newport) equipped with AM-1.5G and UV cut of filters providing simulated light (1 SUN) was used as the light source. The LSV measurement was carried out by sweeping the potential from 0 to $0.7 \mathrm{~V}$ in dark and light conditions.

\section{Results and Discussion}

\subsection{FT-IR Spectroscopic and XRD Analysis}

Figure 2a shows the comparative ATR-FTIR spectrums of g-CN, NiO, and the NiO@g-CN nanocomposite. In the FT-IR spectrum of $\mathrm{g}-\mathrm{CN}$, the absorption band at around $802.25 \mathrm{~cm}^{-1}$ is attributed to the breathing modes of s-triazine units. The absorption bands in the range of 1150 to $1650 \mathrm{~cm}^{-1} \mathrm{are}^{-}$ attributed to the stretching vibrations of aromatic $\mathrm{C}-\mathrm{N}$ heterocycles of $\mathrm{g}-\mathrm{CN}$. The strong absorption band, centered at around $3162.25 \mathrm{~cm}^{-1}$, was attributed to the $\mathrm{N}-\mathrm{H}$ and $\mathrm{O}-\mathrm{H}$ stretching vibration modes, which arises due to incomplete polycondensation of melamine and water molecules adsorbed on the g-CN surface [21]. In the FT-IR spectrum of $\mathrm{NiO}$, the absorption band at $420.41 \mathrm{~cm}^{-1}$ was attributed to the Ni-O bond, and the absorption band at $1363.93 \mathrm{~cm}^{-1}$ was attributed to the carbonate ions. The absorption band at 3414.88 and $1628.13 \mathrm{~cm}^{-1}$ were attributed to the $\mathrm{O}-\mathrm{H}$ stretching vibration and $\mathrm{O}-\mathrm{H}$ deformation mode of the water molecule, respectively [38]. Meanwhile, in the FTIR spectrum of $\mathrm{NiO} @ \mathrm{~g}-\mathrm{CN}$ nanocomposite, the main absorption bands of $\mathrm{g}-\mathrm{CN}$ and $\mathrm{NiO}$ were mostly shifted from lower to higher wavenumbers. This shifting of absorption bands of $\mathrm{g}-\mathrm{CN}$ and $\mathrm{NiO}$ showed the strong interaction between $\mathrm{g}-\mathrm{CN}$ and $\mathrm{NiO}$ and successful formation of $\mathrm{NiO} @ \mathrm{~g}-\mathrm{CN}$ nanocomposite, using the PLAL technique.

XRD patterns were taken to analyze the crystal structure of $\mathrm{g}-\mathrm{CN}, \mathrm{NiO}$, and the $\mathrm{NiO} @ \mathrm{~g}-\mathrm{CN}$

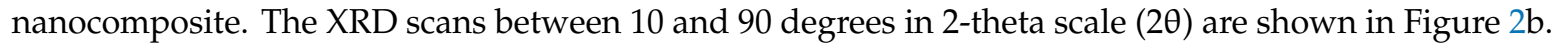
Diffraction planes of $\mathrm{g}-\mathrm{CN}$ and $\mathrm{NiO}$ are indicated in the XRD patterns. In the XRD pattern of g-CN, the peaks observed at around $13.0^{\circ}$ and $27.4^{\circ}$ were unambiguously indexed to (100) and (002) diffraction planes, respectively. The reflection (002) appeared due to interlayer-stacking of the graphitic-like aromatic structure (out-of-plane diffraction), and the reflection (100) appeared due to in-plane ordering of tri-s-triazine units (in-plane diffraction) [37]. The middle spectrum shown in Figure $2 b$ showed the characteristic reflections of cubic ((111), (200), (220), (311), and (222)) phases of the NiO nanoparticles, 
as identified by JCPDS 71-1179 [38]. The XRD pattern of the NiO@g-CN nanocomposite represents the combination peaks of both individual $\mathrm{g}-\mathrm{CN}$ and $\mathrm{NiO}$, without any change in their positions, suggesting that the individual components of the hybrid preserve their crystal structure during the PLAL process.
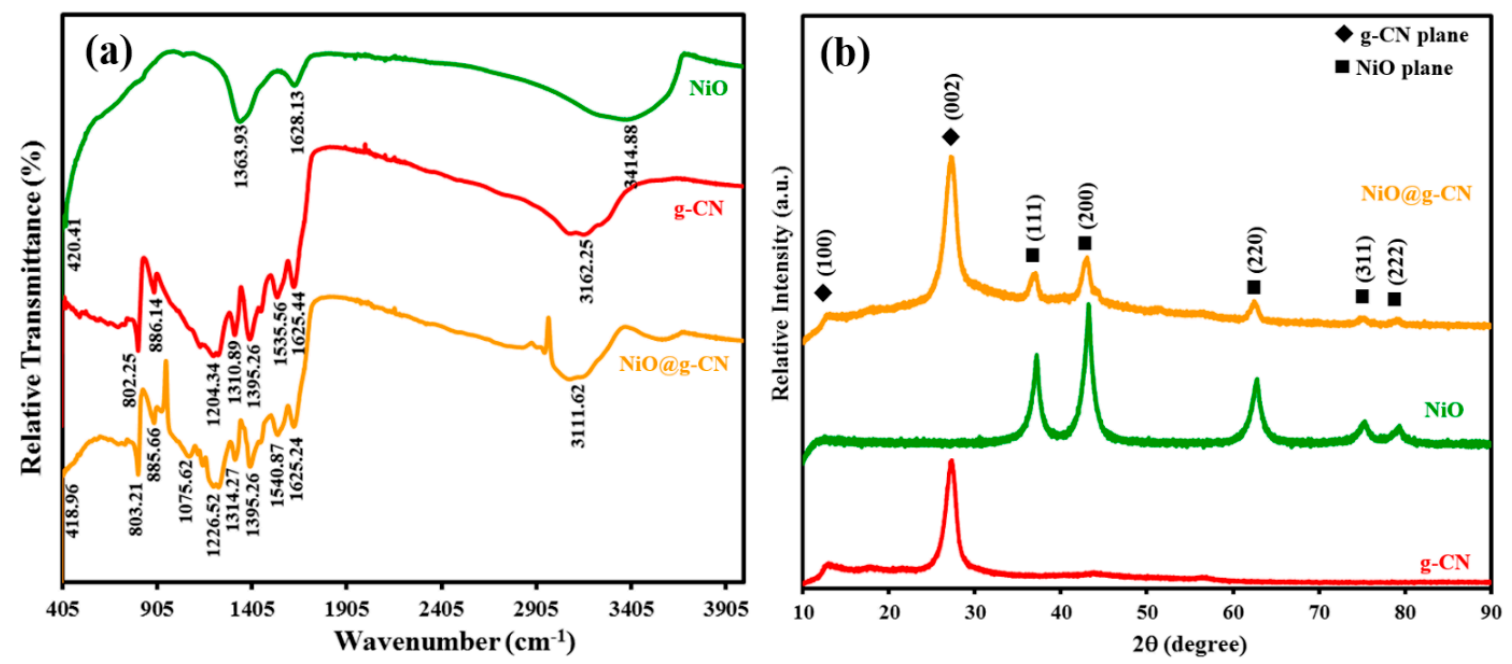

Figure 2. (a) ATR-FTIR spectra of $\mathrm{g}-\mathrm{CN}, \mathrm{NiO}$, and the NiO@g-CN nanocomposite. (b) XRD patterns of pure $\mathrm{g}-\mathrm{CN}$, pure $\mathrm{NiO}$, and the $\mathrm{NiO} @ \mathrm{~g}-\mathrm{CN}$ nanocomposite.

\subsection{Surface Morphology and Elemental Analysis}

The surface morphology and elemental analysis of g-CN, NiO, and the NiO@g-CN nanocomposite were evaluated by FE-SEM and FE-SEM coupled with an EDX system. The FE-SEM images of g-CN, $\mathrm{NiO}$, and the NiO@g-CN nanocomposite are depicted in Figure 3. The pristine g-CN exhibits a sheet-like structure with wrinkles and folding, suggesting its thin nature (Figure 3a). On the contrary, the pure $\mathrm{NiO}$ shows spherical-shaped nanometer-sized particles with agglomeration and cluster formations (Figure 3b). In the FE-SEM image of the NiO@g-CN nanocomposite, the dispersion of NiO nanoparticles can be seen on g-CN sheets (Figure 3c), suggesting the formation of the NiO@g-CN nanocomposite. The thermal shock and the cavitations explosion in PLAL result in the formation of a new cationic and anionic environment on the sample surface, without modifying the basic crystal structure and phase composition. In fact, the defects in the photocatalyst are quite conducive for efficient photocatalytic activity, and this can be a good alternative for adding a dopant. In particular, anion vacancies can effectively regulate the electronic structure and energy band structure of photocatalysts, reduce atom coordination numbers, and provide more active centers, which plays an important role in improving photocatalytic efficiency.

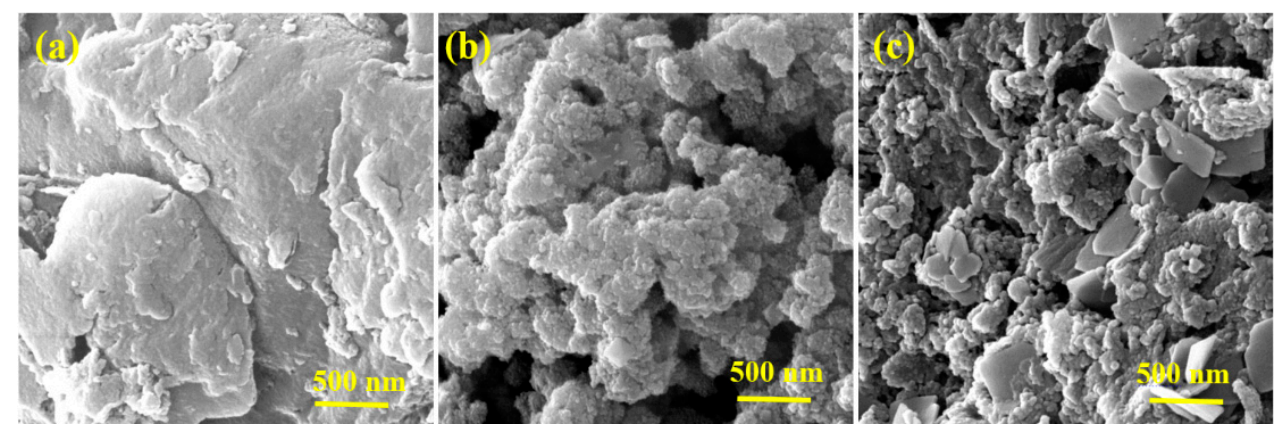

Figure 3. FE-SEM images of pure g-CN (a), pure $\mathrm{NiO}(\mathbf{b})$, and the $\mathrm{NiO} @ \mathrm{~g}-\mathrm{CN}$ nanocomposite (c).

Energy-dispersive X-rays (EDX) spectroscopy was performed for the elemental analysis of the synthesized NiO@g-CN nanocomposite, as shown in Figure 4. The low-magnification FE-SEM image 
of the NiO@g-CN nanocomposite prepared by pulsed laser ablation, with the corresponding EDX spectrum, is shown in Figure $4 a, b$, respectively. The EDX spectrum (area is selected in Figure 4a) of the $\mathrm{NiO} @$ g-CN nanocomposite displayed peaks of $\mathrm{C}, \mathrm{N}, \mathrm{O}$, and $\mathrm{Ni}$, confirming the successful loading of $\mathrm{NiO}$ on $\mathrm{g}-\mathrm{CN}$ sheets (Figure $4 \mathrm{~b}$ ). From corresponding elemental maps (Figure $4 \mathrm{c}-\mathrm{f}$ ), distribution of the elements_carbon (C), nitrogen (N), nickel (Ni), and oxygen (O) — can be seen, indicating the equal ratio of elements in the composite lattice. No peak was detected for the impurity elements in the EDX spectrum, thus proving the pure preparation of nanocomposite and its good agreement with XRD data (Figure 2b). Elemental analysis and EDX mapping images are showing the comparable results. FE-SEM, EDX mapping, and EDX elemental results altogether confirmed the successful synthesis of the NiO@g-CN nanocomposite via the PLAL route.

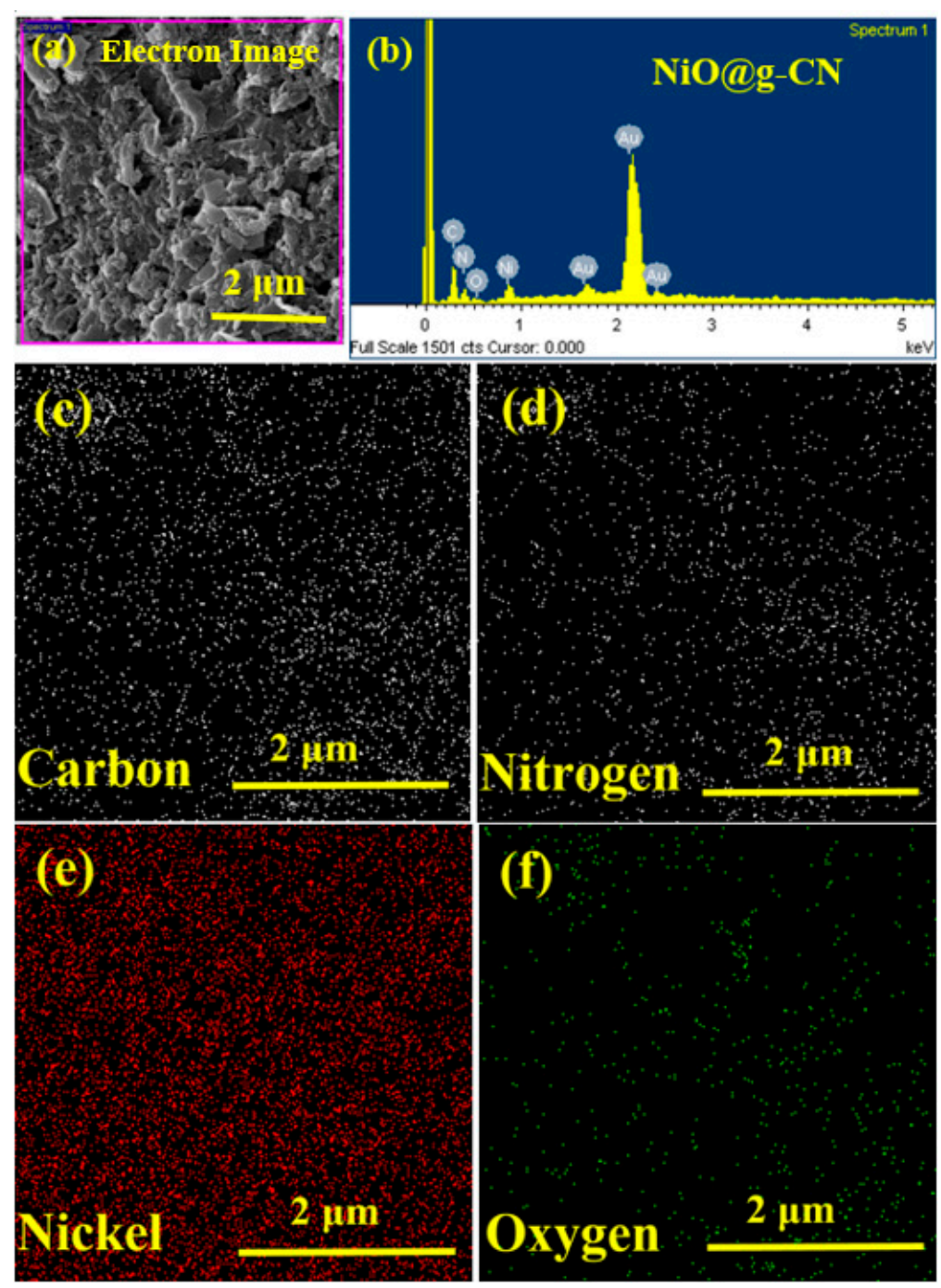

Figure 4. Elemental analysis of the NiO@g-CN nanocomposite. (a) Low-magnification FE-SEM image of the NiO@g-CN nanocomposite, showing the selected area for EDX and elemental mapping analysis. (b) EDX spectrum of NiO@g-CN nanocomposite. Elemental maps for carbon (c), nitrogen (d), nickel (e), and oxygen (f).

The detailed morphology of the NiO@g-CN nanocomposite synthesized via the PLAL technique was evaluated by TEM and high-resolution TEM (HR-TEM) analysis. The TEM and HR-TEM images of the NiO@g-CN nanocomposite at different magnification scales are depicted in Figure 5. From TEM images of the NiO@g-CN nanocomposite (Figure 5a,b), it is clear that the $\mathrm{NiO}$ nanoparticles are uniformly distributed and successfully anchored on the surface of the sheet-like polymeric g-CN 
surface. From HR-TEM images of the NiO@g-CN nanocomposite (Figure $5 c, d$ ), it is obvious that there is close interaction between $\mathrm{g}-\mathrm{CN}$ sheet and $\mathrm{NiO}$ nanoparticles after the formation of the NiO@g-CN nanocomposite by using the PLAL technique. HR-TEM images also demonstrate that NiO nanoparticles were closely connected with g-CN sheets, suggesting the strong interaction between the polymeric g-CN sheets and $\mathrm{NiO}$ nanoparticles.
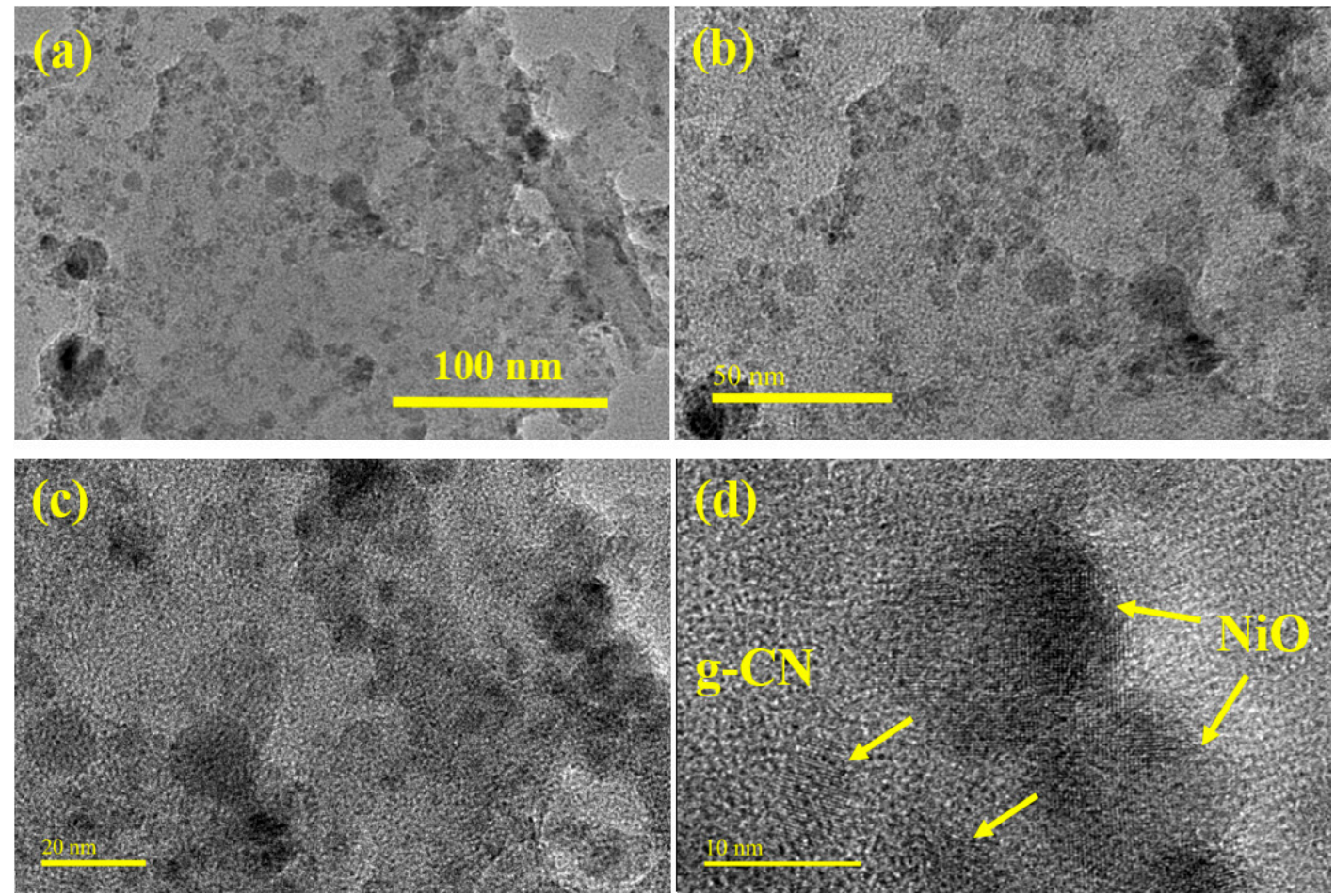

Figure 5. (a-d) TEM and HR-TEM images of NiO@g-CN nanocomposite synthesized via the PLAL technique, at different magnifications. NiO nanoparticles are indicated by yellow-colored arrows anchored on the g-CN surface $(\mathbf{d})$.

\subsection{UV-DRS and PL Spectroscopic Analysis}

The optical absorption properties of g-CN, NiO, and the NiO@g-CN nanocomposite were measured by UV-Vis diffuse reflectance spectroscopic (UV-DRS) analysis. The UV-DRS spectrum of g-CN in Figure 6a displays a sharp absorption peak at around $380 \mathrm{~nm}$ wavelength. It is due to the electronic transition of $\pi-\pi^{*}$ or $n-\pi^{*}$ in the tri-s-triazine ring structure of $\mathrm{g}-\mathrm{CN}$, which is in agreement with other reports [21]. However, the typical absorption of $\mathrm{NiO}$ is in the UV region, due to its broader band-gap energy. By anchoring $\mathrm{NiO}$ on the g-CN surface, we aimed to keep the absorption characteristics of $\mathrm{g}-\mathrm{CN}$ intact, and at the same time forming a heterojunction between $\mathrm{NiO}$ and $\mathrm{g}-\mathrm{CN}$ to promote the charge separation and consequent reduction of charge recombination, which is explained in the next response. Our results show that, compared to pure g-CN and $\mathrm{NiO}$, the $\mathrm{NiO} @ \mathrm{~g}-\mathrm{CN}$ nanocomposite exhibits enhanced photo-absorption in the whole visible-light region. This can be attributed to the strong interaction between the polymeric photocatalyst g-CN and the $\mathrm{NiO}$ nanoparticles, which has been already suggested by other characterization results. The results of UV-DRS demonstrate that the enhanced photo-absorption in the visible-light region by nanocomposite formation of g- $\mathrm{CN}$ and $\mathrm{NiO}$, which is good for visible-light-driven photoelectrochemical water oxidation reaction. 

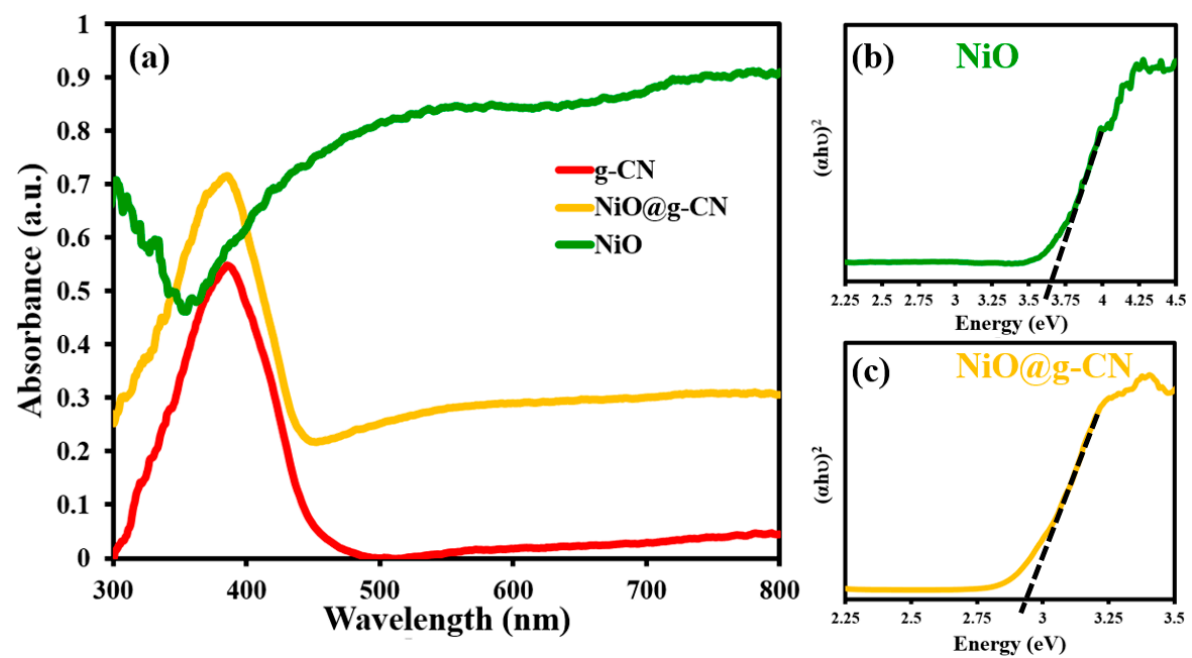

Figure 6. UV-DRS spectra of pure g-CN, pure $\mathrm{NiO}$, and the $\mathrm{NiO} @ \mathrm{~g}-\mathrm{CN}$ nanocomposite (a). Tauc plots of $\mathrm{NiO}(\mathbf{b})$ and the $\mathrm{NiO@g-CN}$ nanocomposite $(\mathbf{c})$.

Tauc plots of $\mathrm{NiO}$ nanoparticles and the NiO@g-CN nanocomposite are depicted in Figure $6 \mathrm{~b}, \mathrm{c}$. A Tauc plot of pure g-CN is depicted in Supplementary Materials Figure S1. The band-gap energies of $\mathrm{NiO}$ nanoparticles and the $\mathrm{NiO} @ \mathrm{~g}-\mathrm{CN}$ nanocomposite were estimated from the Tauc plot, by extrapolating the straight portion of $(\alpha \mathrm{h} v)^{2}$ versus $(\mathrm{h} v)$ plot. The estimated $\mathrm{E}_{\mathrm{g}}$ value of $\mathrm{NiO}$ nanoparticles and the NiO@g-CN nanocomposite by extrapolating the straight portion of $(\alpha \mathrm{h} v)^{2}$ versus (hv) plot are $\sim 3.6 \mathrm{eV}$ and $\sim 2.85 \mathrm{eV}$, respectively, as shown in Figure $6 \mathrm{~b}$,c. The presence of the $\mathrm{g}-\mathrm{CN}$ in the NiO@g-CN nanocomposite has proved effectiveness in shifting the band gap of $\mathrm{NiO}$ nanoparticles toward the visible-light range of the solar-spectrum. The decreased bandgap of NiO@g-CN nanocomposite means that lower-energy radiation can stimulate the photocatalysts to generate electron-hole pairs. Therefore, the better photocatalytic performance of the NiO@g-CN nanocomposite can be expected by longer-wavelength electromagnetic radiation.

The electron-hole recombination behavior of the g-CN and NiO@g-CN nanocomposite photocatalysts was examined by photoluminescence spectroscopy at an excitation wavelength of $320 \mathrm{~nm}$. Figure 7 shows the PL spectra of g-CN and the NiO@g-CN nanocomposite photocatalysts from 350 to $600 \mathrm{~nm}$ emission-wavelength range. For both g-CN and the NiO@g-CN nanocomposite photocatalysts, the emission band was centered at $\sim 450 \mathrm{~nm}$. However, the emission intensity of the pristine g-CN after anchoring of $\mathrm{NiO}$ nanoparticles via the PLAL technique was effectively decreased, demonstrating the reduced electron-hole recombination rate and enhanced photocatalytic activity of the NiO@g-CN nanocomposite photocatalyst. PL emission in $\mathrm{g}-\mathrm{CN}$ is due to the photo-generated electron-hole recombination that takes place, when the electrons in the conduction band transfer to the valance band. When $\mathrm{NiO}$ is anchored on the polymeric surface of $\mathrm{g}-\mathrm{CN}$, this results in the formation of a p-n heterojunction between the p-type $\mathrm{NiO}$ and n-type g-CN semiconductors, which promotes the charge separation due to the electric field in the junction and consequently results in the reduction of charge recombination. This reduced-charge recombination is reflected as a diminished PL-peak intensity that is quite evident in our PL spectrum in Figure 7. 


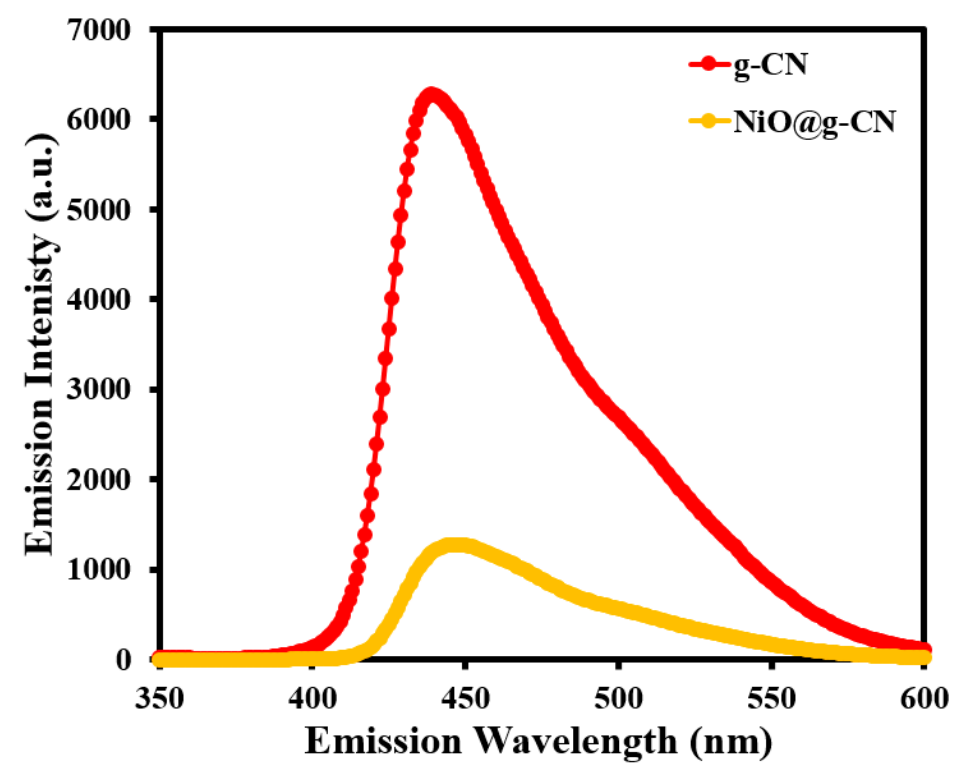

Figure 7. Photoluminescence spectra of g-CN and the NiO@g-CN nanocomposite.

\subsection{Photoelectrochemical Measurements}

The electrodes of g-CN and the NiO@g-CN nanocomposite photocatalyst were fabricated and were used as photoanodes, to study the photoelectrochemical (PEC) water-splitting performance under simulated one-sun-light irradiation. The PEC water-splitting performance of the g-CN and $\mathrm{NiO@g-CN} \mathrm{nanocomposite} \mathrm{photoanodes} \mathrm{was} \mathrm{evaluated} \mathrm{by} \mathrm{measuring} \mathrm{the} \mathrm{current} \mathrm{density} \mathrm{in} \mathrm{LSV}$ measurements under dark and light exposure. The comparative I-V characteristics of g-CN and NiO@g-CN nanocomposite photoanodes under dark and light irradiations are shown in Figure 8a. It is clear from the I-V characteristics that the magnitude of photocurrent density increased with increasing the voltage sweep for $\mathrm{g}-\mathrm{CN}$ and $\mathrm{NiO} @ g-\mathrm{CN}$ nanocomposite photoanodes under dark and light irradiations. Upon exposure to light, the current density of the g-CN photoanode was increased from $\sim 0.92 \mu \mathrm{A} / \mathrm{cm}^{2}$ (dark current) to $\sim 2.0 \mu \mathrm{A} / \mathrm{cm}^{2}$, at 0.7 volt, versus SCE. Similarly, on exposure to visible light, the current density of the NiO@g-CN nanocomposite photoanode was increased from $\sim 3.72 \mu \mathrm{A} / \mathrm{cm}^{2}$ (dark current) to $\sim 8.65 \mu \mathrm{A} / \mathrm{cm}^{2}$, at 0.7 volt, versus SCE. The enhancement in the current densities of g-CN and the NiO@g-CN nanocomposite photoanodes after exposure to light demonstrates the photo-responsive feature of the synthesized catalysts. The findings of I-V characteristics for PEC water-splitting demonstrate that, as compared to the g-CN photoanode, the NiO@g-CN nanocomposite photoanode showed a four-fold enhancement in the photocurrent density under visible-light irradiations and thus improved PEC performance. The lower photocurrent response of pristine g-CN could be attributed to high photo-generated charge recombination in g-CN and the improved photocurrent response of NiO@g-CN nanocomposite photoanode produced by reduced photo-generated charge recombination in NiO@g-CN nanocomposite by anchoring of $\mathrm{NiO}$ nanoparticles in the g-CN sheets via the PLAL technique, which is supported by PL results in Figure 7.

The photocurrent density of g-CN and the $\mathrm{NiO} @ \mathrm{~g}-\mathrm{CN}$ nanocomposite photoanodes was also measured under a chopped light-irradiation condition (light on/off cycle), at a constant 0.7-volt bias voltage. Chronoamperometric photocurrent-time responses of g-CN and the NiO@g-CN nanocomposite photoanodes under periodically chopped visible-light irradiations (light on/off cycle) are depicted in Figure 8b. The current density was measured for $\sim 350 \mathrm{~s}$, with $30 \mathrm{~s}$ of intervals at an applied bias of 0.7-volt, vs. SCE. The result indicated that, upon exposure to visible light, the photocurrent generated instantaneously and reached a steady state and fell sharply as soon as the light was switched off. There was an initial slight decrease in the photocurrent, which became stable with time, indicating good stability of photoanodes under visible-light irradiation and constant applied potential. 

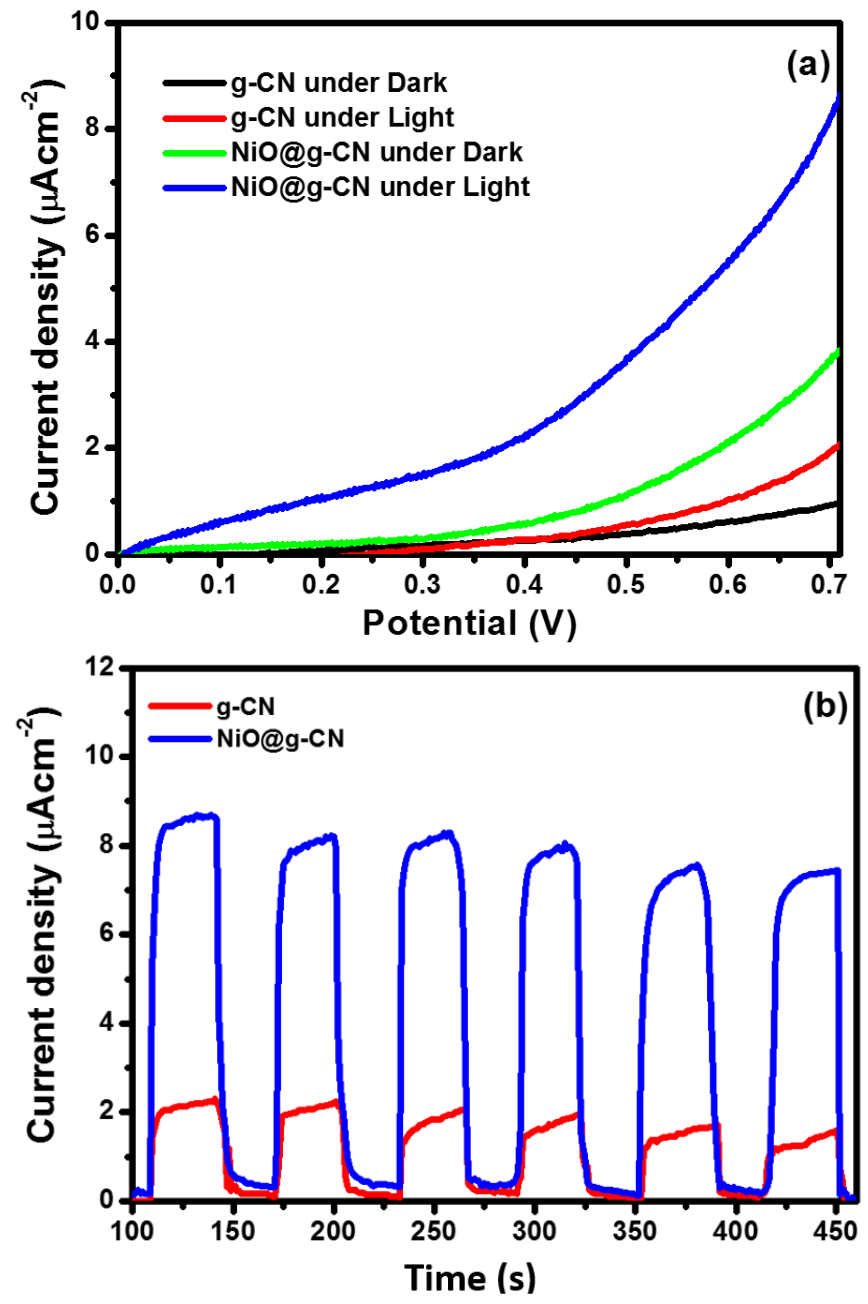

Figure 8. Linear-sweep voltammetric response of g-CN and NiO@g-CN nanocomposite photoanodes under dark and visible-light irradiation (a). Chronoamperometric photocurrent-time responses of g-CN and $\mathrm{NiO} @ \mathrm{~g}-\mathrm{CN}$ nanocomposite photoanodes under periodically chopped visible-light irradiations (light on/off cycle) (b).

The photocurrent density of g-CN and NiO@g-CN nanocomposite photoanodes was also measured under continuous visible-light irradiations condition, at a constant 0.7 -volt bias voltage vs. SCE, to measure the stability of the fabricated photoanodes in the PEC water-splitting experiment. Chronoamperometric stability testing of g-CN and NiO@g-CN nanocomposite photoanodes in the PEC water-splitting experiment under continuous visible-light irradiations is shown in Figure 9a. After $2250 \mathrm{~s}$ of continuous visible-light irradiations, the photocurrent density of g-CN and NiO@g-CN nanocomposite photoanodes was slightly decreased, and that decrease can be attributed to photo-corrosion of the fabricated photoanodes in the electrolyte solution.

The charge-transfer behavior in g-CN and NiO@g-CN nanocomposite photoanodes was evaluated by EIS (electrochemical impedance spectroscopy) measurements. Figure $9 \mathrm{~b}$ shows the Nyquist plots of g-CN and NiO@g-CN nanocomposite photoanodes. Generally, the smallest radius of the arc denotes more effective separation and transport of photo-generated charge carriers. In Figure 9b, NiO@g-CN nanocomposite photoanode displays the smallest radius of the arc compared with the pristine g-CN photoanode, suggesting the fastest interfacial charge transport process and lowest charge-transfer resistance of photo-generated charge carriers in the NiO@g-CN nanocomposite photoanode. 

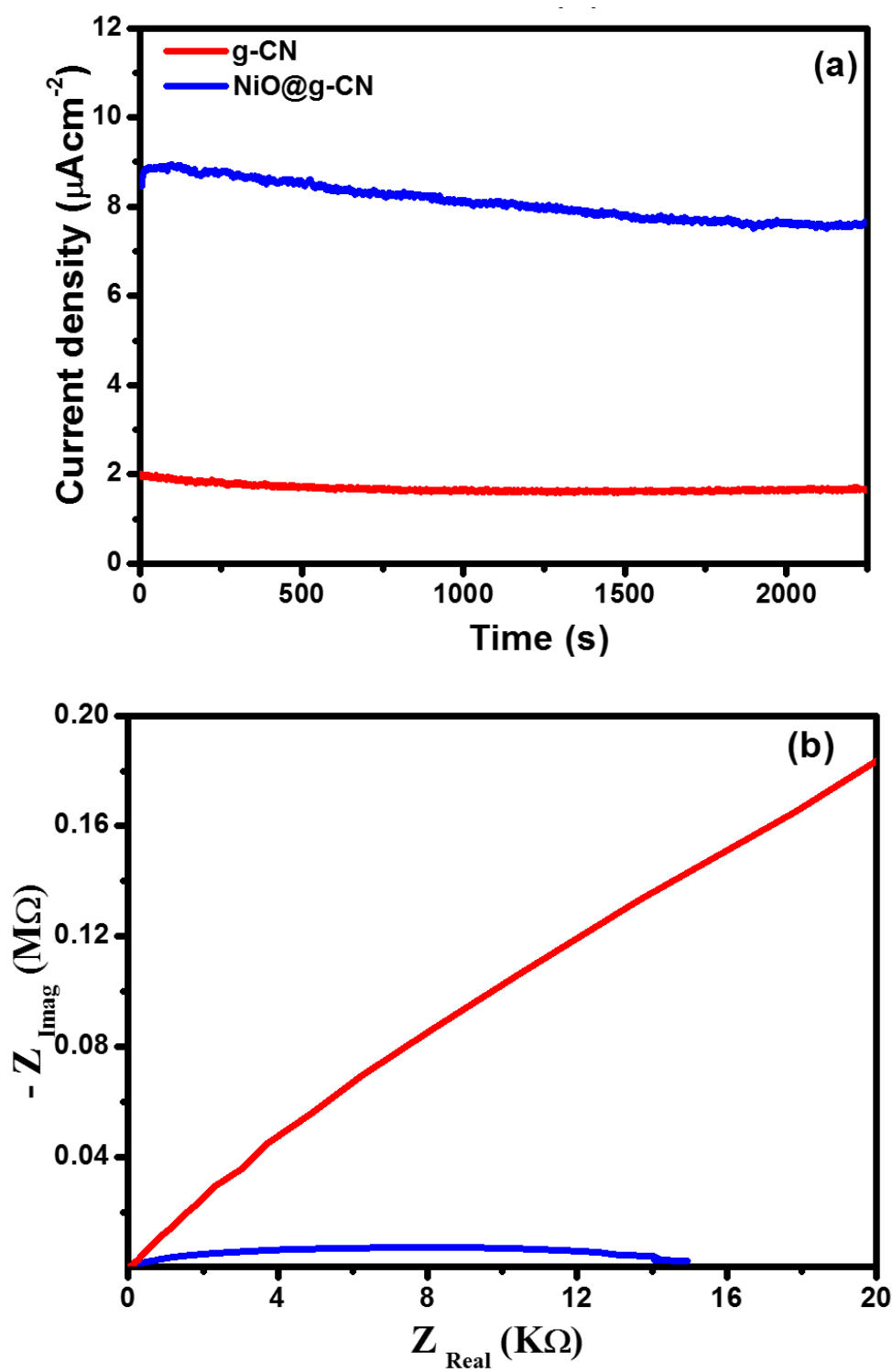

Figure 9. Chronoamperometric stability testing of g-CN and the NiO@g-CN nanocomposite photoanodes under continuous visible-light irradiations (a). Nyquist plots of g-CN and NiO@g-CN nanocomposite photoanodes (b).

Based on the PEC measurements, a schematic sketch of the photoelectrochemical working mechanism of NiO@g-CN nanocomposite photoanode for the water-splitting experiment is presented in Figure 10, showing the photo-oxidation and reduction processes taking place during the reaction, where the NiO@g-CN nanocomposite is used as a photoanode under visible-light irradiations. 


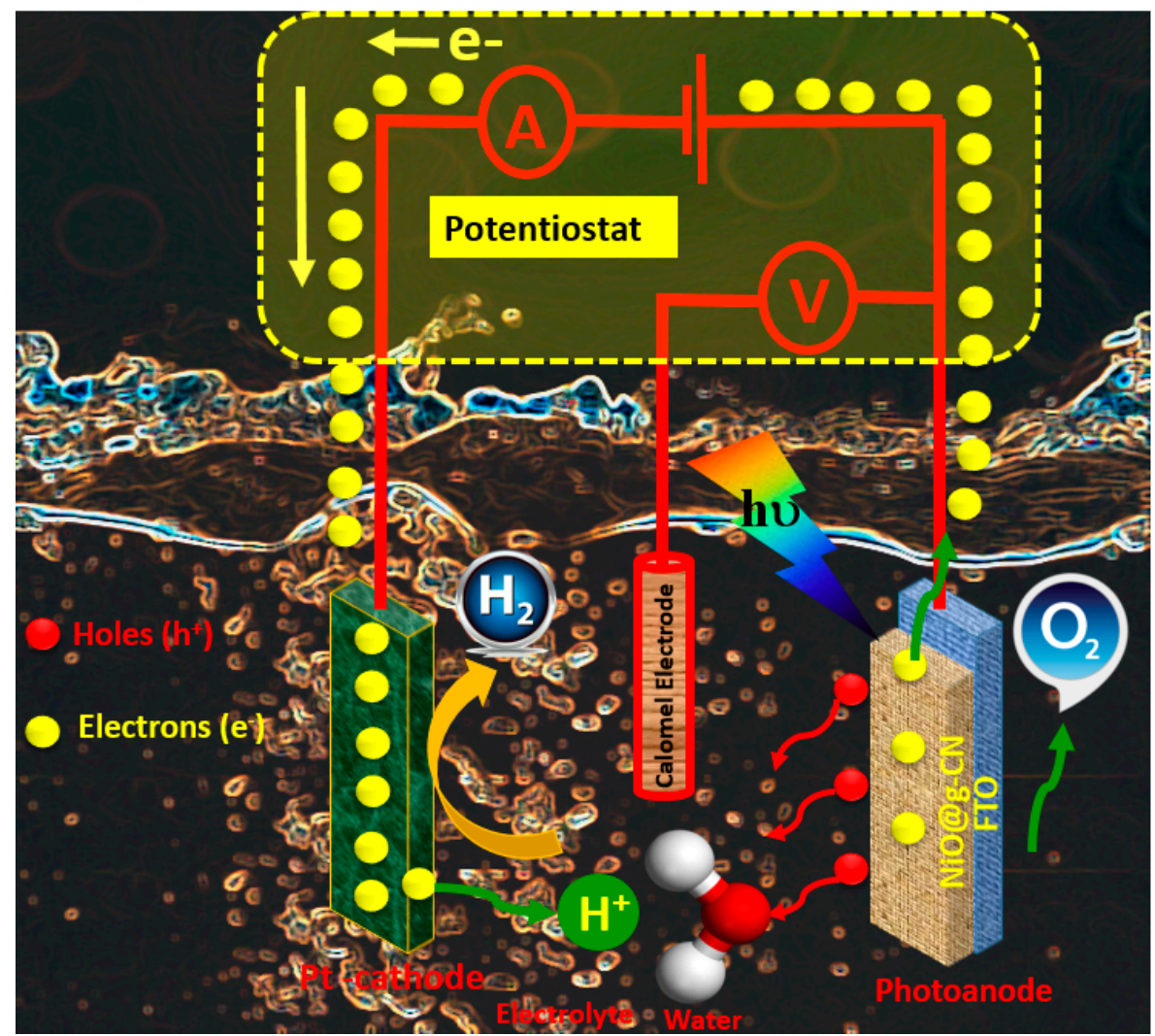

Figure 10. Schematic sketch of proposed photoelectrochemical working mechanism of the NiO@g-CN nanocomposite photoanode for water splitting.

\section{Conclusions}

A visible-light-active NiO@g-CN nanocomposite was synthesized by pulsed laser ablation in liquid, using a focused beam of $532 \mathrm{~nm}$ pulsed laser source. The morphological, structural, and elemental analyses carried out in this work confirmed the anchoring of $\mathrm{NiO}$ nanoparticles on $\mathrm{g}-\mathrm{CN}$ sheets. The first effect of this nanocomposite formation (anchoring of $\mathrm{NiO}$ nanoparticles on g-CN sheets) is manifested as enhanced visible-light absorption of $\mathrm{NiO} @ \mathrm{~g}-\mathrm{CN}$ in the absorption spectra deduced from diffuse reflectance spectra, and the second effect is manifested as reduced electron hole recombination observed as the reduction of photoluminescence intensity of NiO@g-CN in the PL spectra. The improved material characteristics in NiO@g-CN culminated in four-fold higher photocurrent generated by the NiO@g-CN photo anode compared to the anchoring of $\mathrm{NiO}$ nanoparticles on g-CN sheets anchoring of $\mathrm{NiO}$ nanoparticles on $\mathrm{g}-\mathrm{CN}$ sheets by pure g-CN photoanode.

Supplementary Materials: The following are available online at http://www.mdpi.com/2079-4991/10/6/1098/s1, Figure S1: Tauc's plot of g-CN.

Author Contributions: Conceptualization, investigation, visualization, data curation, methodology, writingoriginal draft preparation. writing-review \& editing, U.B.; investigation, methodology, data curation, A.K.; resources, project administration, methodology, writing-review \& editing, M.A.G.; methodology, investigation, writing-review \& editing, M.A.D.; project administration, resources, funding acquisition, methodology, investigation, writing-review \& editing, W.S.F. All authors have read and agreed to the published version of the manuscript.

Funding: This research was funded by Deanship of Scientific Research (DSR) at King Fahd University of Petroleum \& Minerals through project No. DISC1801.

Acknowledgments: The author(s) would like to acknowledge the support provided by the Deanship of Scientific Research (DSR) at King Fahd University of Petroleum \& Minerals (KFUPM) for funding this work through project No. DISC1801.

Conflicts of Interest: On behalf of all authors, the corresponding author states that there is no conflict of interest. 


\section{References}

1. Staffell, I.; Scamman, D.; Abad, A.V.; Balcombe, P.; Dodds, P.E.; Ekins, P.; Shah, N.; Ward, K.R. The role of hydrogen and fuel cells in the global energy system. Energy Environ. Sci. 2019, 12, 463-491. [CrossRef]

2. Rosen, M.A.; Koohi-Fayegh, S. The prospects for hydrogen as an energy carrier: An overview of hydrogen energy and hydrogen energy systems. Energ. Ecol. Environ. 2016, 1, 10-29. [CrossRef]

3. Panwar, N.L.; Kaushik, S.C.; Kothari, S. Role of renewable energy sources in environmental protection: A review. Renew. Sust. Energ. Rev. 2011, 15, 1513-1524. [CrossRef]

4. Brandon, N.P.; Kurban, Z. Clean energy and the hydrogen economy. Philos. Trans. A Math Phys. Eng. Sci. 2017, 375, 20160400. [CrossRef] [PubMed]

5. Raza, A.; Gholami, R.; Rezaee, R.; Rasouli, V.; Rabiei, M. Significant aspects of carbon capture and storage-A review. Petroleum 2019, 5, 335-340. [CrossRef]

6. Anderson, S.; Newell, R. Prospects for carbon capture and storage technologies. Annu. Rev. Environ. Resour. 2004, 29, 109-142. [CrossRef]

7. Yang, H.; Zhang, C.; Gao, P.; Wang, H.; Li, X.; Zhong, L.; Sun, W.W.Y. A review of the catalytic hydrogenation of carbon dioxide into value-added hydrocarbons. Catal. Sci. Technol. 2017, 7, 4580-4598. [CrossRef]

8. Liu, M.; Yi, Y.; Wang, L.; Guo, H.; Bogaerts, A. Hydrogenation of carbon dioxide to value-added chemicals by heterogeneous catalysis and plasma catalysis. Catalysts 2019, 9, 275. [CrossRef]

9. Fujishima, A.; Honda, K. Electrochemical photolysis of water at a semiconductor electrode. Nature 1972, 238, 37-38. [CrossRef]

10. Gondal, M.A.; Hameed, A.; Yamani, Z.H.; Al-Suwaiyan, A. Production of hydrogen and oxygen by water splitting using laser photo-catalysis over $\mathrm{Fe}_{2} \mathrm{O}_{3}$. Appl. Catal. A 2004, 268, 159-167. [CrossRef]

11. Gondal, M.A.; Dastageer, M.A.; Oloore, L.E.; Baig, U. Laser induced selective photo-catalytic reduction of $\mathrm{CO}_{2}$ into methanol using $\mathrm{In}_{2} \mathrm{O}_{3}-\mathrm{WO}_{3}$ nano-composite. J. Photochem. Photobiol. A 2017, 343, 40-50. [CrossRef]

12. Gondal, M.A.; Dastageer, M.A.; Oloore, L.E.; Baig, U.; Rashid, S.G. Enhanced photo-catalytic activity of ordered mesoporous indium oxide nanocrystals in the conversion of $\mathrm{CO}_{2}$ into methanol. J. Environ. Sci. Health A Tox. Hazard. Subst. Environ. Eng. 2017, 52, 785-793. [CrossRef] [PubMed]

13. Baig, U.; Gondal, M.A.; Ilyas, A.M. Band gap engineered polymeric-inorganic nanocomposite catalysts: Synthesis, isothermal stability, photocatalytic activity and photovoltaic performance. J. Mater. Sci. Technol. 2017, 33, 547-557. [CrossRef]

14. Gondal, M.A.; Dastageer, M.A.; Khalil, A.; Rashid, S.G.; Baig, U. Photo-catalytic deactivation of sulfate reducing bacteria-A comparative study with different catalysts and the preeminence of Pd-loaded $\mathrm{WO}_{3}$ nanoparticles. RSC Adv. 2015, 5, 51399-51406. [CrossRef]

15. Younas, M.; Gondal, M.A.; Dastageer, M.A.; Baig, U. Fabrication of cost effective and efficient dye sensitized solar cells with $\mathrm{WO}_{3}-\mathrm{TiO}_{2}$ nanocomposites as photoanode and MWCNT as Pt-free counter electrode. Ceram. Int. 2019, 45, 936-947. [CrossRef]

16. Gondal, M.A.; Ilyas, A.M.; Baig, U. Pulsed laser ablation in liquid synthesis of $\mathrm{ZnO} / \mathrm{TiO}_{2}$ nanocomposite catalyst with enhanced photovoltaic and photocatalytic performance. Ceram. Int. 2016, 42, 13151-13160. [CrossRef]

17. Kumar, R.V.; Coto, M.; Ghosh, S. Visible-light active photocatalysis: Nanostructured catalyst design. Mech. Appl. 2018, 18, 499-526.

18. Xie, X.; Kretschmer, K.; Wang, G. Advances in gra-phene-based semiconductor photocatalysts for solar energy conversion: Fundamentals and materials engineering. Nanoscale 2015, 7, 13278-13292. [CrossRef]

19. Ong, W.J.; Tan, L.L.; Ng, Y.H.; Yong, S.T.; Chai, S.P. Graphitic carbon nitride $\left(\mathrm{g}-\mathrm{C}_{3} \mathrm{~N}_{4}\right)$-based photocatalysts for arti-ficial photosynthesis and environmental remediation: Are we a step closer to achieving sustainability? Chem. Rev. 2016, 116, 7159-7329. [CrossRef]

20. Qin, J.; Wang, S.; Ren, H.; Hou, Y.; Wang, X. The photocatalytic reduction of $\mathrm{CO}_{2}$ was investigated with g- $\mathrm{C}_{3} \mathrm{~N}_{4}$ powder. Appl. Catal. B Environ. 2017, 217, 65-80.

21. Gondal, M.A.; Lais, A.; Dastageer, M.A.; Yang, D.; Shen, K.; Chang, X. Photocatalytic conversion of $\mathrm{CO}_{2}$ into methanol using graphitic carbon nitride under solar, UV laser and broadband radiations. Int. J. Energy Res. 2017, 41, 2162-2172. [CrossRef] 
22. Yi, Z.; Ye, J.; Kikugawa, N.; Kako, T.; Ouyang, S.; williams, S.; Yang, H.; Cao, J.; Luo, W.; $\mathrm{Li}, \mathrm{Z}$. An orthophosphate semiconductor with photo-oxidation properties under visible-light irradiation. Nat. Mater. 2010, 9, 559-564. [CrossRef] [PubMed]

23. Wang, F.; Feng, Y.; Chen, P.; Wang, Y.; Su, Y.; Zhang, Q.; Zeng, Y.; Xie, Z.; Liu, H. Photocatalytic degradation of fluoroquinolone antibiotics using ordered mesoporous $\mathrm{g}-\mathrm{C}_{3} \mathrm{~N}_{4}$ under simulated sunlight irradiation. Appl. Catal. B Environ. 2018, 227, 114-122. [CrossRef]

24. Wang, K.; Li, Q.; Liu, B.; Cheng, B.; Ho, W.; Yu, J. Sulfur-doped g- $\mathrm{C}_{3} \mathrm{~N}_{4}$ with enhanced photocatalytic $\mathrm{CO}_{2}$-reduction performance. Appl. Catal. B Environ. 2015, 176-177, 44-52. [CrossRef]

25. Chen, P.; Wang, F.; Zhang, Q.; Su, Y.; Shen, L.; Yao, K.; Chen, Z.F.; Liu, Y.; Cai, Z.; Lv, W.; et al. Photocatalytic degradation of clofibric acid by $g-\mathrm{C}_{3} \mathrm{~N}_{4} / \mathrm{P} 25$ composites under simulated sunlight irradiation. Chemosphere 2017, 172, 193-200. [CrossRef]

26. Guo, F.; Shi, W.; Wang, H.; Han, M.; Li, H.; Huang, H.; Liu, Y.; Kang, Z. Facile fabrication of a CoO/g-C $\mathrm{C}_{4}$ p-n heterojunction with enhanced photocatalytic activity and stability of tetracycline degradation under visible light. Catal. Sci. Technol. 2017, 7, 3325-3331. [CrossRef]

27. Yin, S.; Di, J.; Li, M.; Sun, Y.; Xia, J.; Xu, H.; Fan, W.; Li, H. Ionic liquid-assisted synthesis and improved photocatalytic activity of $\mathrm{p}-\mathrm{n}$ junction $\mathrm{g}_{-} \mathrm{C}_{3} \mathrm{~N}_{4} / \mathrm{BiOCl}$. J. Mater. Sci. 2016, 51, 4769-4777. [CrossRef]

28. Ma, S.; Song, Y.; Xu, P.; Fu, X.; Ye, Z.; Xue, J. Facile one-step synthesis of Cu1.96Sg-C ${ }_{3} \mathrm{~N}_{4} 0 \mathrm{D} / 2 \mathrm{D}$ p-n heterojunction with enhanced visible light photo-activity toward cipro-floxacin degradation. Mater. Lett. 2017, 213, 370-373. [CrossRef]

29. Zhou, X.H.; Liu, R.; Sun, K.; Friedrich, D.; McDowell, M.T.; Yang, F.; Omelchenko, S.T.; Saadi, F.H.; Nielander, A.C.; Yalamanchili, S.; et al. Interface engineering of the photoelectrochemical performance of Ni-oxide-coated n-Si photoanodes by atomic-layer deposition of ultrathin films of cobalt oxide. Energy Environ. Sci. 2015, 8, 2644-2649. [CrossRef]

30. Sun, K.; Kuang, Y.; Verlage, E.; Brunschwig, B.S.; Tu, C.W.; Lewis, N.S. Sputtered NiOx films for stabilization of p+n-InP photoanodes for solar-driven water oxidation. Adv. Energy Mater. 2015, 5, 1402276. [CrossRef]

31. Yuksel, R.; Buyukcakir, O.; Panda, P.K.; Lee, S.H.; Jiang, Y.; Singh, D.; Hansen, S.; Adelung, R.; Mishra, Y.K.; Ahuja, R.; et al. Necklace-like nitrogen-doped tubular carbon 3D frameworks for electrochemical energy storage. Adv. Funct. Mater. 2020, 30, 1909725. [CrossRef]

32. Pnada, P.K.; Grigoriev, A.; Mishra, Y.K.; Ahuja, R. Progress in supercapacitors: Roles of two dimensional nanotubular materials. Nanoscale Adv. 2020, 2, 70-108. [CrossRef]

33. Malik, R.; Tomer, V.T.; Mishra, Y.K.; Lin, L. Functional gas sensing nanomaterials: A panoramic view. Appl. Phys. Rev. 2020, 7, 021301. [CrossRef]

34. Zhao, X.F.; Panda, P.K.; Singh, D.; Yang, X.Y.; Mishra, Y.K.; Ahuja, R. 2D g- $\mathrm{C}_{3} \mathrm{~N}_{4}$ monolayer for amino acids sequencing. Appl. Surf. Sci. 2020, in press. [CrossRef]

35. Gröttrup, J.; Schütt, F.; Smazna, D.; Lupan, O.; Adelung, R.; Mishra, Y.K. Porous ceramics based on hybrid inorganic tetrapodal networks for efficient photocatalysis and water purification. Ceram. Int. 2017, 43, 14915-14922. [CrossRef]

36. Gondal, M.A.; Ilyas, A.M.; Baig, U. Facile synthesis of silicon carbide-titanium dioxide semiconducting nanocomposite using pulsed laser ablation technique and its performance in photovoltaic dye sensitized solar cell and photocatalytic water purification. Appl. Surf. Sci. 2016, 378, 8-14. [CrossRef]

37. Yang, D.; Gondal, M.A.; Yamani, Z.H.; Baig, U.; Qiao, X.; Liu, G.; Xu, Q.; Xiang, D. 532 nm nanosecond pulse laser triggered synthesis of $\mathrm{ZnO}_{2}$ nanoparticles via a fast ablation technique in liquid and their photocatalytic performance. Mat. Sci. Semicon. Proc. 2017, 57, 124-131. [CrossRef]

38. Baig, U.; Uddin, M.K.; Gondal, M.A. Removal of hazardous azo dye from water using synthetic nano adsorbent: Facile synthesis, characterization, adsorption, regeneration and design of experiments. Colloids Surf. A 2020, 584, 124031. [CrossRef]

(C) 2020 by the authors. Licensee MDPI, Basel, Switzerland. This article is an open access article distributed under the terms and conditions of the Creative Commons Attribution (CC BY) license (http://creativecommons.org/licenses/by/4.0/). 